\title{
GMDH Neural Networks - Based modeling of variable power inductor
}

\author{
Peyman Koohi ${ }^{1 *}$, Parham Mohammadi ${ }^{2}$, Rahim Samanbakhsh ${ }^{1}$ and Federico.M. Ibanez ${ }^{1}$ \\ 1 Skolkovo Institute of Science and Technology (Skoltech), Moscow, Russia \\ 2 Department of Electrical Engineering and Computer Science, York University, Toronto, Canada \\ * Correspondence: Peyman.koohi@skoltech.ru
}

\begin{abstract}
In this paper, the Group Method of Data Handling (GMDH) type of neural networks is used for the inductance calculation of variable inductors. The relation between the inductance of the inductor in the linear and nonlinear regions is investigated, and parameters such as the voltage across the inductor, bias current, and ac current are taken into account. The experimental setup is used for generating the data needed for training the neural network. Over 800 experiments were conducted and were used for training and validation of the neural network results. The results are compared with the reluctance equivalent circuit method, and they show a much better accuracy. The proposed method can be used for the calculation of various magnetic components, and it is not limited to variable inductors.
\end{abstract}

Keywords: Variable inductor, GMDH - Neural Networks, inductance, magnetic component calculation

\section{Introduction}

Power electronic converters are moving toward higher frequencies and higher power densities thanks to new power switch technologies such as GaN or SiC. Accordingly, a great number of researchers are focusing on the calculation of magnetic components[1][2][3][4][5] for such applications. Particularly, variable inductors have been gaining a tremendous amount of attention because of their application in optimizing the control of power electronics converters [6][7][8][9][10][11][12][13][14][15].

Resonant converters are one of the most attractive power electronics converters because of their inherent soft-switching capability[16]. Although they can achieve softswitching easily, which leads to higher power densities, their variable frequency control creates several problems, such as difficulty in designing proper Electro-Magnetic Interference (EMI) filters[17]. In addition, another big challenge is that a wide range of output voltage cannot easily be achieved because it leads to the loss of soft-switching capability. Variable inductance can be a solution to all of these issues[18].

Dual active bridge (DAB) converters are also one of the most practical power electronic converters in the industry because of their capability to have galvanic isolation using high-frequency transformers. Meanwhile, their control systems are highly dependent on the transformer's leakage inductance, which leads to complicated and nonlinear control algorithms[19]. Variable inductors can also be used for controlling the series inductance (or leakage inductance) of the transformer; hence linearization of the control algorithm can be easily achieved[15][20][4].

One of the challenges associated with the use of variable inductance is estimating the inductance since the operation point of the variable inductance is in the nonlinear region of the B-H curve, which cannot be estimated properly by linear modeling methods.

Three main methods have been used in the literature for modeling magnetic components [17]:

1. Finite Element Method 
2. Gyrator-Capacitor Model

3. Reluctance equivalent circuit

The finite element method is one of the most used methods for calculating magnetic components because of its capability to solve nonlinear equations based on numerical methods [21][22]. They are two challenges associated with the finite element method; one is that this method requires a really high computational power, and the other one is that linking the results from the finite element method to the electrical method is not straightforward [17]. Reluctance equivalent circuit is a straightforward procedure for calculating inductance[23][24], but it does not have enough accuracy in the nonlinear region of the B-H curve, which leads to an inaccurate design of the magnetic components [17].

Neural networks have been used in modeling magnetic components. In [25] multilayer perceptron neural network has been used with a combination of finite element methods in order to calculate the leakage inductance of a transformer. While the results are promising, there are two major disadvantages associated with this methodology. One is that the neural network is being fed by the data created by the finite element method, which adds up the error of the simulations to the error of the neural networks, which consequently leads to inaccurate results. The latter disadvantage is that model extracted from neural networks is still hidden and distributed over the network, and It is not possible to use the archived model in other research.

Group Method of Data Handling (GMDH) neural networks has been used in the literature for extracting models of nonlinear phenomenal[26][27][28]; the model extracted from this type of neural networks is expressed mathematically in terms of high order polynomials and can be used for future users. Experimental results are being used in this paper for feeding the GMDH neural networks, which adds to the accuracy of the model.

In this paper, Section 2 presents an overview of the variable inductance structure is investigated. Section 3 shows the reluctance equivalent method circuit of the structure. Section 4 introduces GMDH neural networks. The experimental setup is investigated in Section 4, and results of the GMDH neural network extracted model and reluctance equivalent circuit will be compared in Section 5. There, it is shown that GMDH neural network extracted model is showing much better accurate results. Finally, Section 6 concludes the paper and shown future works.

\section{Construction of a variable inductor}

The proposed variable inductor is based on two E-shape core, which has an air gap on the center arm, and sidearms do not have an air gap. Unlike constant inductors, the variable inductor has two groups of windings. The main winding is located on the center leg, and two symmetrical windings (bias windings) are on the side legs. Figure 1 shows the construction of a double E-shape core-based variable inductor [29].

The main winding is connected to an AC source, and a DC current source supplied the bias windings. Two bias windings on sidearms are connected in series and reverse polarity[29]. Passing AC current through the main winding generates an AC flux, which flows through the center arm, then separates into two equal parts and goes to the side arms. In bias winding, by injection of a DC current, a DC flux goes through the ungapped arms (side arms). The air gap in the center arm, which is embraced by AC winding, minimizes the magnetomotive force (MMF) of the DC control winding; therefore, the inductance of the main winding can be controlled by applying a small current. In a variable inductor, the main and bias windings are decoupled; hence, any modification in the AC source doesn't generate an AC signal in control windings [23]. 


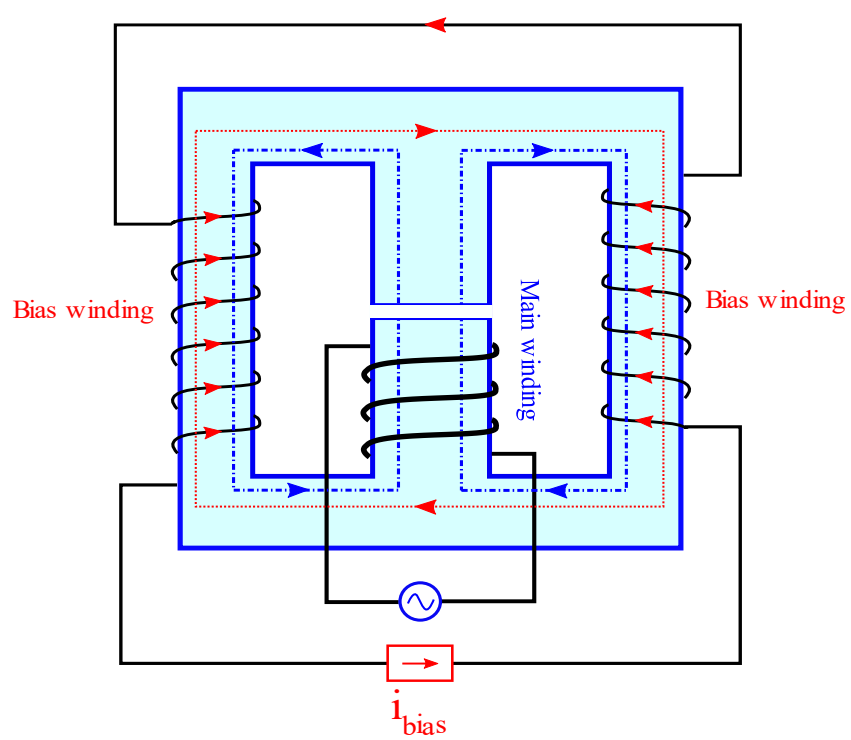

Figure 1. Construction of double E core variable inductor.

Figure 2 shows the operation principles of a double E core-based variable inductor, explained by $\mathrm{B}(\mathrm{H})$ curves of both ungapped arms of the variable inductor. The DC bias current produces a DC MMF on sidearms, which can adjust the operating point toward the nonlinear region and modify the inductance of the main winding [23].

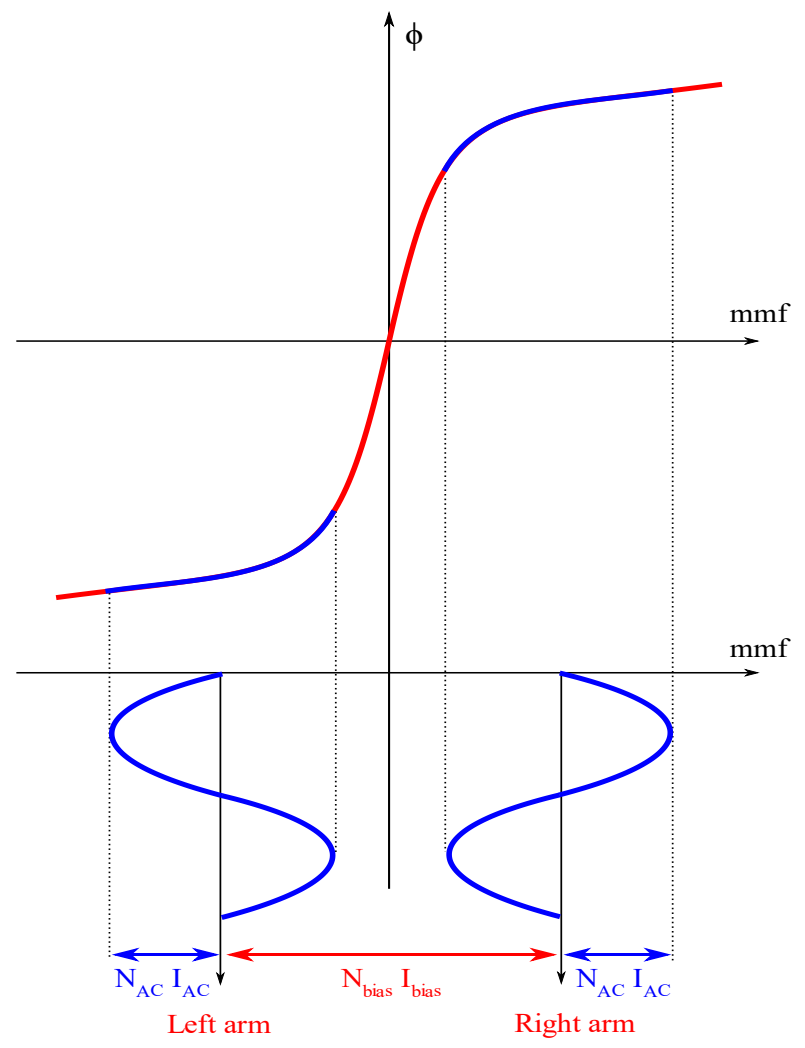

Figure 2. Operation principles of a double E core-based variable inductor.

In order to find the expression of the inductance, the reluctance model of the variable inductor is needed. 


\section{Reluctance based model}

A variable inductor can be expressed by a reluctance equivalent circuit. Figure 3 represents the equivalent reluctance circuit of a variable inductor. $R_{L}, R_{R}$, and $R_{c}$ respectively donate on the reluctance of the left arm, right arm, and the center arm; in addition, the air gap in the center arm is expressed by RG. On the other hand, the generated magnetomotive forces (MMFs) are shown as voltage sources. The voltage source on the center arm (FAC) expresses the produced AC MMF by the main winding. The voltage sources on side legs (Fbias) represent the DC MMF generated by bias windings connected in opposite polarity in parallel[17].

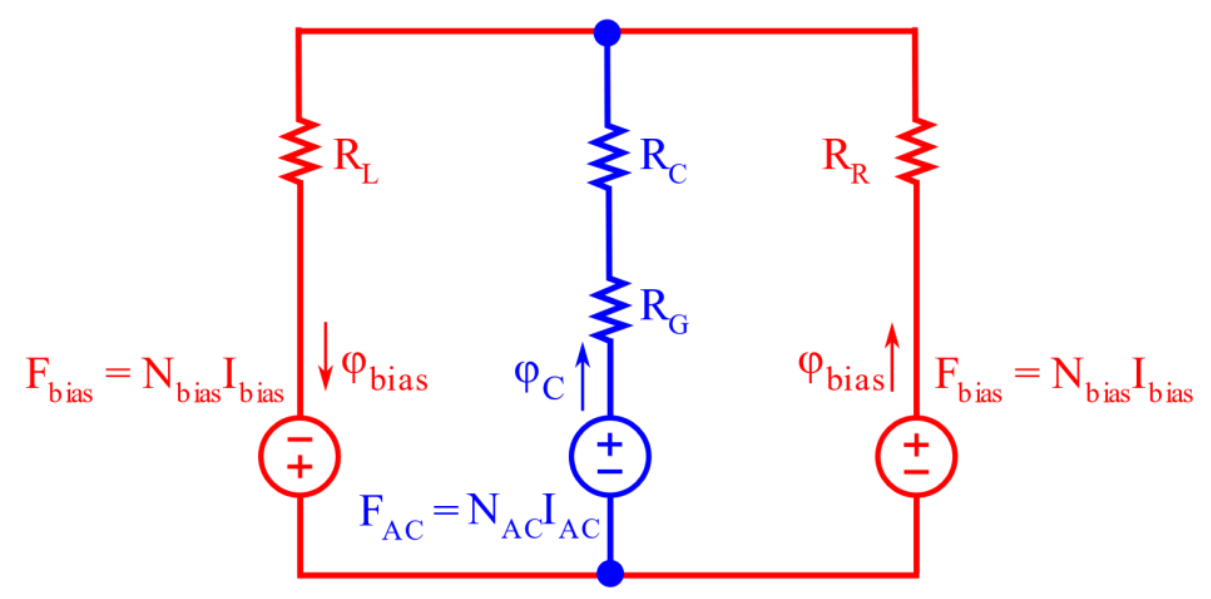

Figure 3. Reluctance equivalent of a double E core variable inductor.

Conventionally, the reluctance equivalent circuit is made of three elements which are:

1. Constant reluctance model: this model generally donates on non-ferromagnetic elements in the core construction; therefore, air gap models are a constant reluctance. This model is represented as a resistor, and its value is stated by Equation (1).

$$
R_{G}=\frac{l_{0}}{\mu_{G} A_{G} X_{f}}
$$

In Equation (1), $\mu_{0}$ is the permeability of the vacuum or free space which is equal to $4 \pi \times 10^{-7} \cdot l_{G}$ and $A_{G}$ respectively donates on the length and section of the air gap. $X_{f}$ Represents the fringing coefficient which is close to 1 .

2. Variable reluctance model: the variable reluctance represents the characteristics of the magnetic material in the nonlinear region. Equation (2) shows the expression of the variable reluctance:

$$
R_{m}=\frac{l_{m}}{\mu_{0} \mu_{m} A_{m} X_{f}}
$$

In Equation (2), $\mu_{m}$ is relative permability of the magnetic material. $A_{m}$ and $l_{m}$ donates on the section and length of the variable reluctance element.

3. Winding model: As we discussed before, passing an electric current through a winding, magnetomotive force (MMF) will be produced; hence, a winding is modeled as a voltage source where can be expressed by (3) and (4).

$$
\begin{gathered}
F(t)=N \cdot I(t) \\
v(t)=N \cdot \frac{d \emptyset(t)}{d(t)}=N \cdot A \cdot \frac{d B(t)}{d t}
\end{gathered}
$$


where $v(t)$ and $I(t)$ are voltage and current passing through the inductor's winding, $F(t)$ and $\mathrm{N}$ are magnetomotive force (MMF) and turns of wound wires, $\varnothing(t)$ and $B(t)$ express the magnetic flux and magnetic flux density.

In Equation (2), the length and cross-section of the inductor, also the fringing factor is fixed, but the permeability of the magnetic material can be changed nonlinearly, according to the operating point. The general expression of the magnetic permeability is stated by Equation (5), where $\mu$ is magnetic permeability, $\mathrm{B}$ and $\mathrm{H}$ are magnetic flux density and magnetic flux intensity.

$$
\mu=\frac{B}{H}
$$

The differential magnetic permeability provides a more accurate definition of permeability. Equation (6) shows the expression of differential permeability.

$$
\mu_{d}=\frac{d B}{d H}
$$

Based on Equation (6), the differential magnetic permeability is the slope of the B-H curve of the magnetic material. Figure (4) shows the B-H curve and magnetic permeability of N87 ferromagnetic material. In the linear region, the slope of the B-H curve is high and almost constant. At the corner part, the magnetic permeability decreases significantly. In the saturated region, the rate of permeability change is much lower, according to the linear characteristic of the B-H curve in the saturation region.

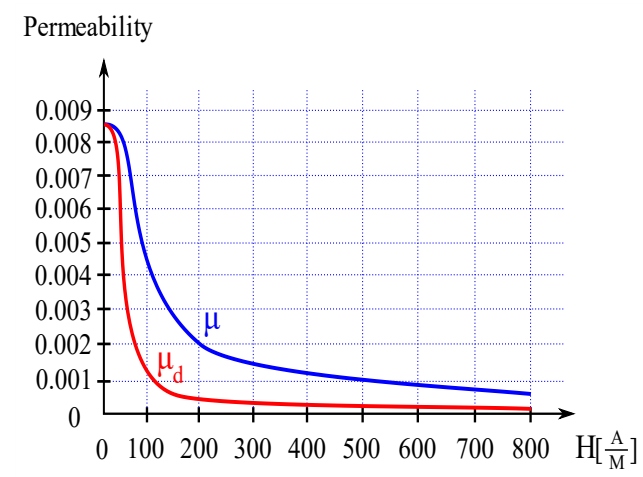

(a)

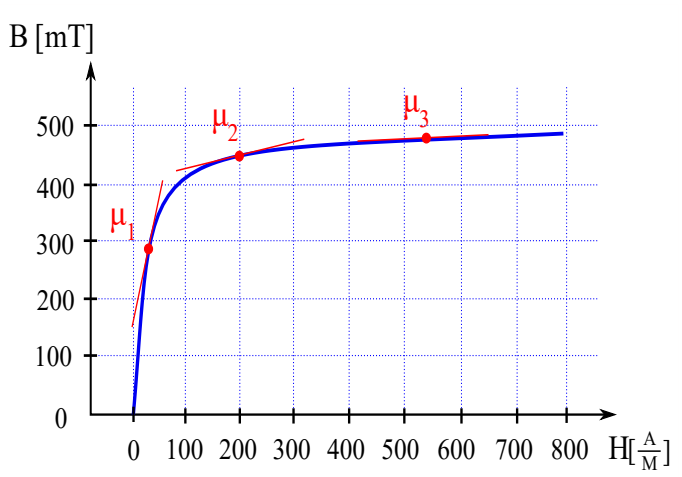

(b)

Figure 4. (a) Magnetic permeability characteristics of N87 ferromagnetic material at $25^{\circ} \mathrm{C}$. (b) B-H characteristic of $\mathrm{N} 87$ ferromagnetic material at $25{ }^{\circ} \mathrm{C}$.

The general definition, the inductance, is stated by Equation (7), which represents that inductance is the ratio of the total flux to the current passing through the winding.

$$
L=\frac{N_{a c} \emptyset_{c}}{i_{a c}}
$$

where $N_{a c}$ is the turns of main winding, which is wound on the center arm of double Eshape core, and $\emptyset_{c}$ is the ac magnetic flux of the main winding. This definition is applicable for materials with constant permeability, like air. To express the inductance of materials with nonlinear characteristic, like ferromagnetic materials, the differential inductance is required. Equation (8) represents the differential inductance.

$$
d L=\frac{N_{a c} d \emptyset_{c}}{d i_{a c}}
$$


By considering the reluctance model in inductance calculation, the value of inductance will follow Equation (9).

$$
L=\frac{N_{a c}^{2}}{R_{C}+R_{g a p}+R_{L} \| R_{R}}
$$

where $N_{a c}$ is turns of main winding, and $R_{C}, R_{g a p}, R_{L}, R_{R}$ Donates on the center arm, air gap left and right arm reluctance. As discussed before, the fringing coefficient $\left(X_{f}\right)$ is closed to 1 for small air gaps. To have a more accurate result in inductance calculation, we can consider the fringing coefficient using Equation (10).

$$
X_{f}=1+\frac{l_{g}}{\sqrt{A_{C}}} \ln \left(\frac{2 h_{w}}{l_{g}}\right)
$$

where $l_{g}$ is the length of the air gap, $A_{C}$ is section of main winding on the center arm, and $h_{w}$ is the height of the main winding. Finally, the value of inductance is the multiplication of Equation (9) and the fringing coefficient. Equation (11) shows the value of inductance.

$$
L^{\prime}=L \cdot X_{f}
$$

In this section, based on experimental prototype specification, the reluctance model of the variable inductor is calculated. Figure 5 shows the experimental prototype and dimension of the implemented ferromagnetic core.

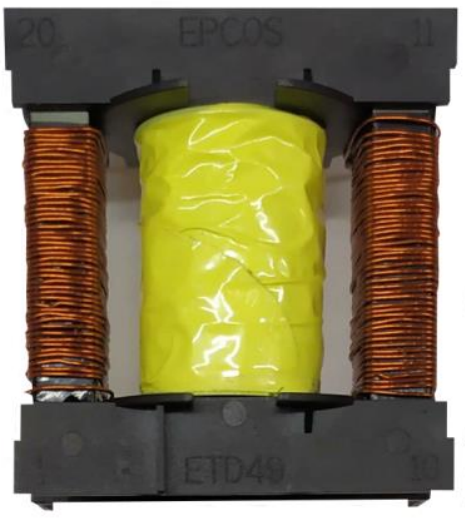

(a)

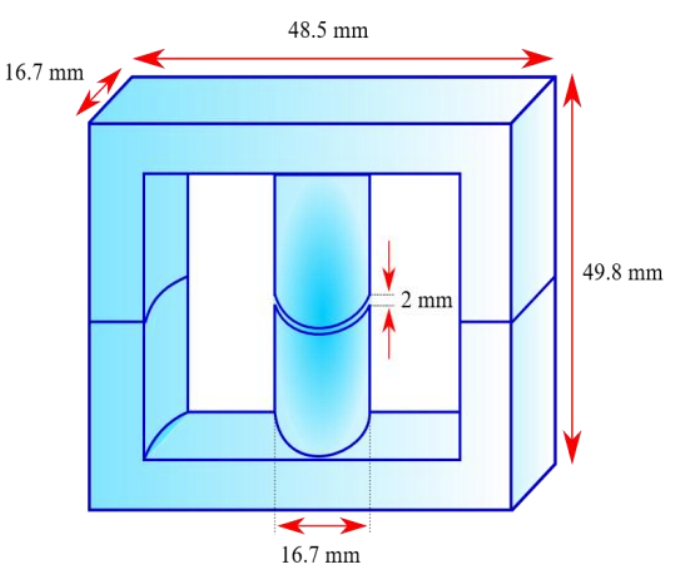

(b)

Figure 5. (a) experimental prototype of the variable inductor. (b) dimension of the implemented ferromagnetic core.

Table 1 shows the specification of the implemented variable inductor. 
Table 1. Specification of an experimental prototype of the variable inductor.

\begin{tabular}{cc}
\hline Parameter & Specification \\
\hline Core size & ETD49/25/16 \\
Magnetic material & $\mathrm{N} 87$ \\
$\mathrm{~N}_{\mathrm{ac}}$ & 24 \\
$\mathrm{~N}_{\mathrm{bias}}$ & $90(45+45)$ \\
$l_{\mathrm{g}}$ & $2 \mathrm{~mm}$ \\
$\mathrm{X}_{\mathrm{f}}$ & 1.6 \\
$\Delta \mathrm{L}$ & $42-105 \mu \mathrm{H}$ \\
\hline
\end{tabular}

Figure 6 shows the main winding inductance change as a function bias current according to experimental prototype specification and the reluctance model. According to Figure 6, the difference between the reluctance model and the experimental value of inductance will increase by increasing the bias current. In order to improve the accuracy of the model, GMDH neural networks are introduced in the next section.

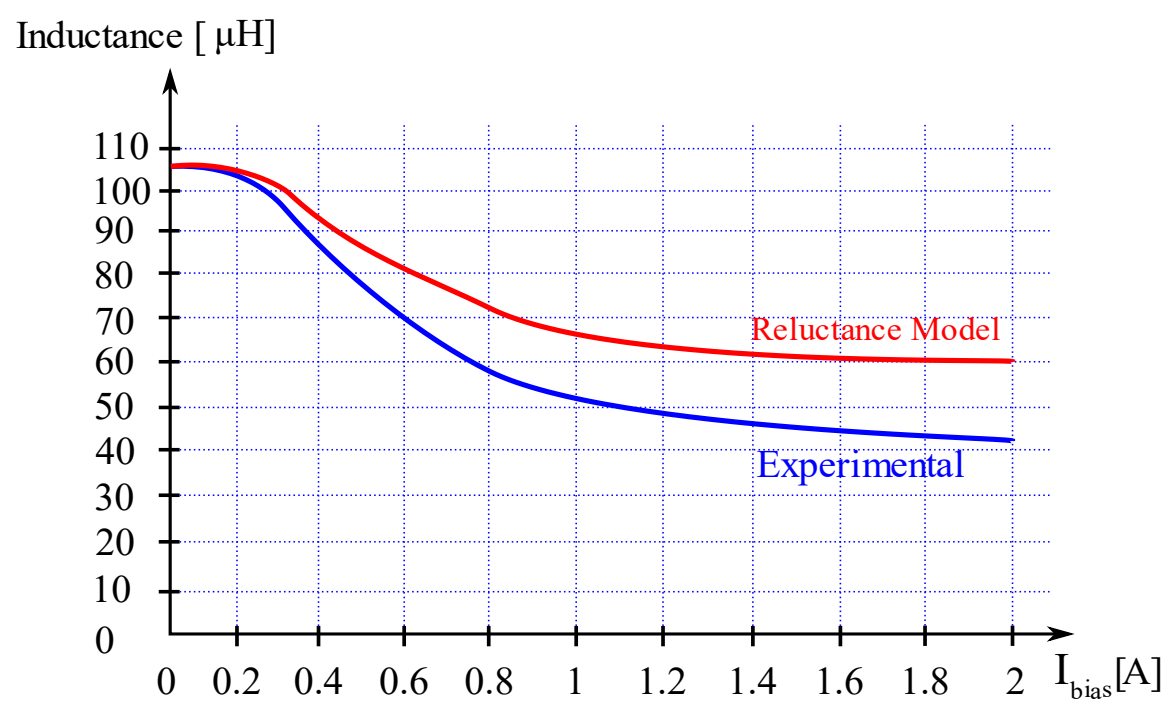

Figure 6. Inductance value as a function of the bias winding current in the experimental and reluctance model.

\section{GMDH Neural network-based model}

GMDH neural networks are used to construct a functional relationship in a feedforward network [27]. They can be considered as a polynomial neural network where the activation functions are polynomial functions instead of conventional activation functions [30]. Unlike conventional neural networks where the model is hidden and distributed over the whole network, the final model of GMDH is expressed mathematically in a nonlinear function called the Volterra series, also known as Kolmogorov-Gabor polynomial, expressed as [27], [30] :

$$
\begin{gathered}
y=a_{0}+\sum_{i=1}^{M} a_{i} x_{i}+\sum_{i=1}^{M} \sum_{j=1}^{M} a_{i j} x_{i} x_{j}+ \\
\sum_{i=1}^{M} \sum_{j=1}^{M} \sum_{k=1}^{M} a_{i j k} x_{i} x_{j} x_{k}
\end{gathered}
$$


Figure 7 illustrates the neuron architecture of the GMDH neural network, as it can be seen that each of the neurons has a polynomial function instead of the conventional activation function used in neural networks [28].

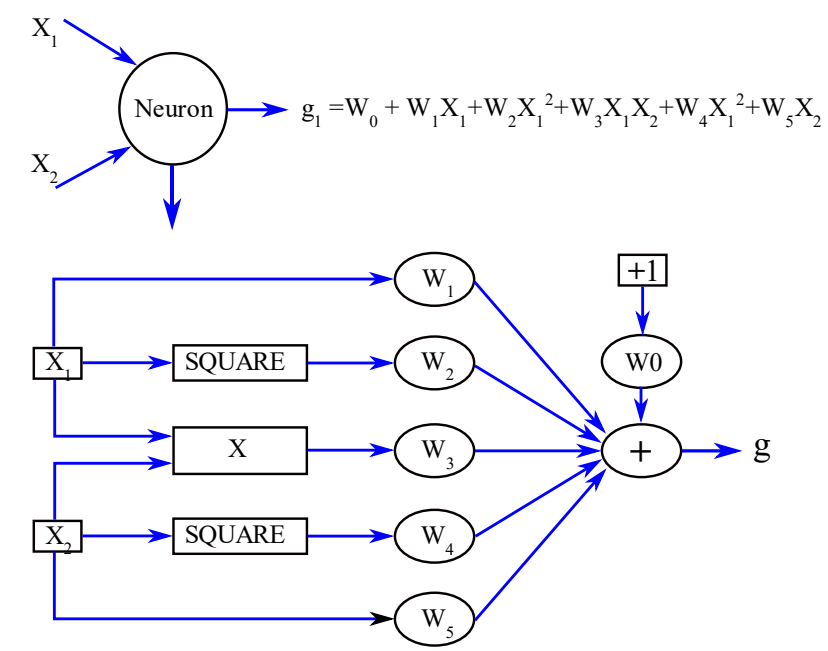

Figure 7. GMDH neuron architecture.

Figure 8 depicts the derived model based on the experiments. The weights of each neuron are presented in Table 2. The experimental setup and the accuracy of the derived model will be discussed in the next sections. The architecture, the gains and the activation function that are presented in this section compromise the mathematical model of the variable inductor.

The input of the models is based on both the MMFs of the main and the auxiliary windings. Two new features have been implemented based on the cubic root of the main and auxiliary windings in order to simplify the derived network. The network's output is the ratio between the inductance at zero bias current and the inductance at the increased bias current. The inductance at zero bias current can easily be calculated with linear models since the inductance is designed in a way that the operating point lies within the linear part of the B-H curve 

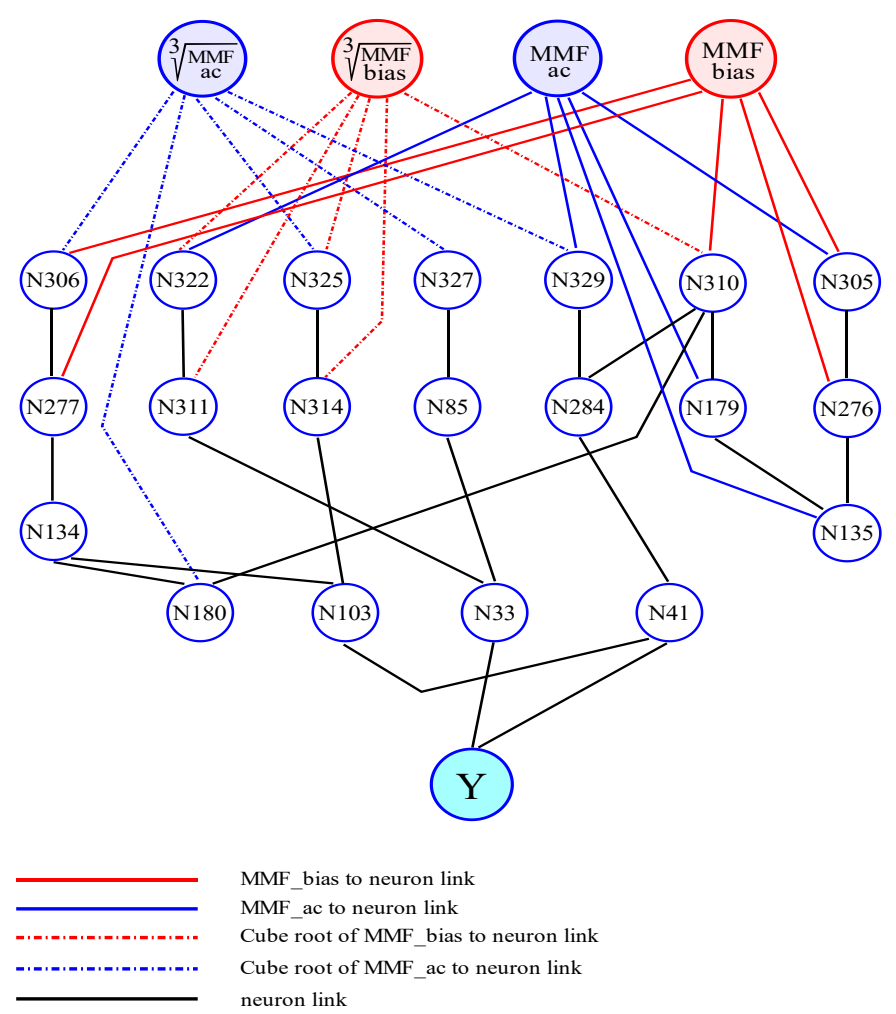

Figure 8. Derived model of the neural network.

Table 2. Weight of neurons.

\begin{tabular}{ccccccc}
\hline Neuron & $\mathbf{W}_{\mathbf{0}}$ & $\mathbf{W}_{\mathbf{1}}$ & $\mathbf{W}_{\mathbf{2}}$ & $\mathbf{W}_{\mathbf{3}}$ & $\mathbf{W}_{\mathbf{4}}$ & $\mathbf{W}_{\mathbf{5}}$ \\
\hline N329 & -94.6785 & 25.9154 & 0.0182929 & -3.0103 & -92.2754 & 152.169 \\
N327 & -10.5916 & 3.93968 & 0.355502 & -2.84035 & -4.89075 & 15.7505 \\
N325 & 1.14732 & -0.215016 & -0.00965425 & 0.0398079 & -0.0405591 & 0.126089 \\
N322 & 1.24326 & -0.00166146 & $-5.68012 \mathrm{e}-05$ & 0.00159507 & -0.0101711 & -0.135934 \\
N314 & 39.7287 & -9.48158 & 0.565074 & 8.30358 & 30.2229 & -68.4667 \\
N311 & 45.6577 & -11.0082 & 0.663207 & 9.5557 & 34.2153 & -78.2002 \\
N310 & 0.997198 & -0.0733067 & $-6.15095 \mathrm{e}-05$ & 0.0106867 & 0.126864 & -0.0547432 \\
N306 & 0.911905 & -0.00830284 & $2.7178 \mathrm{e}-05$ & 0 & 0 & 0.0391064 \\
N305 & 0.972457 & -0.00834315 & $2.73913 \mathrm{e}-05$ & 0 & $-1.73935 \mathrm{e}-05$ & 0.00261303 \\
N284 & 0.146116 & 0.93016 & -0.214717 & 0.715395 & -0.284496 & -0.304743 \\
N277 & -1.02463 & 0.0097835 & $-2.14464 \mathrm{e}-05$ & -0.0095779 & -0.886964 & 2.93002 \\
N276 & -0.978251 & 0.00935551 & $-2.00959 \mathrm{e}-05$ & -0.00948724 & -0.890723 & 2.88724 \\
N180 & -0.947393 & 0.402541 & -0.042551 & -0.14487 & -0.164266 & 1.73245 \\
N179 & -0.245069 & 0.00647496 & $-4.27001 \mathrm{e}-05$ & -0.00337935 & -0.117166 & 1.32068 \\
N135 & -0.0197178 & -0.702624 & 27.6819 & -52.8795 & 25.1427 & 1.76902 \\
N134 & -0.0165042 & -0.174235 & 26.6126 & -50.6644 & 24.0054 & 1.85245 \\
N103 & 0.00702396 & 0.142155 & 0 & -0.0785871 & 0.0980534 & 0.965952 \\
N85 & 0.00760783 & 0.0597712 & -0.210859 & 0.262902 & -0.057125 & 0.932176 \\
N41 & -0.000288163 & -0.719367 & 29.5532 & -58.2219 & 28.6751 & 1.71292 \\
N33 & -0.000863671 & 0.174235 & 0.965952 & -2.1224 & 1.1504 & 0.829764 \\
Y & 0.00294764 & -0.258061 & 111.294 & 223.754 & -112.45 & 1.24837 \\
\hline
\end{tabular}

\section{Experimental Test Setup}

As discussed previously, over 800 test data are collected to train with the neural network. These data are collected by modifying the bias winding current and main winding current (AC current). Figure 9 shows the experimental test diagram. The test diagram includes an active bridge that generates squared AC voltage and is connected to the main 
winding. A variable DC voltage source supplies the bias winding, and a 10-Ohm resistor is in series to limit the current.

Figure 10 shows the experimental hardware setup. The detailed specification of the variable inductor is represented in Table 1, and Table 3 shows the general elements of the implemented experimental setup.

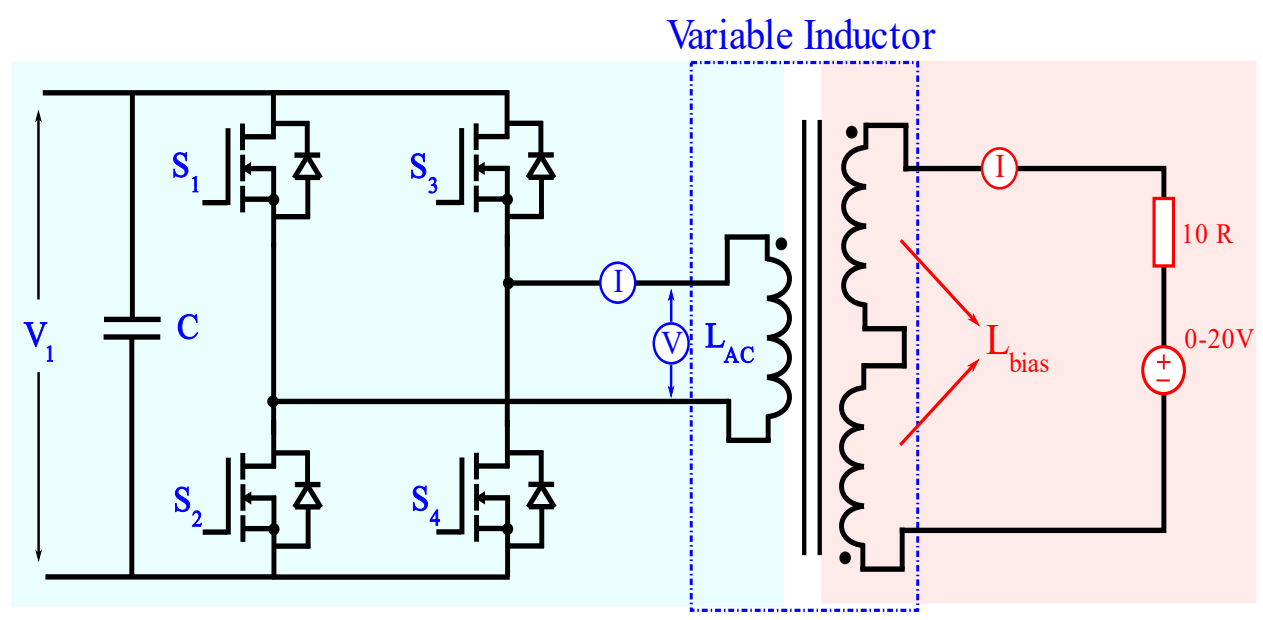

Figure 9. Experimental test diagram of the variable inductor.

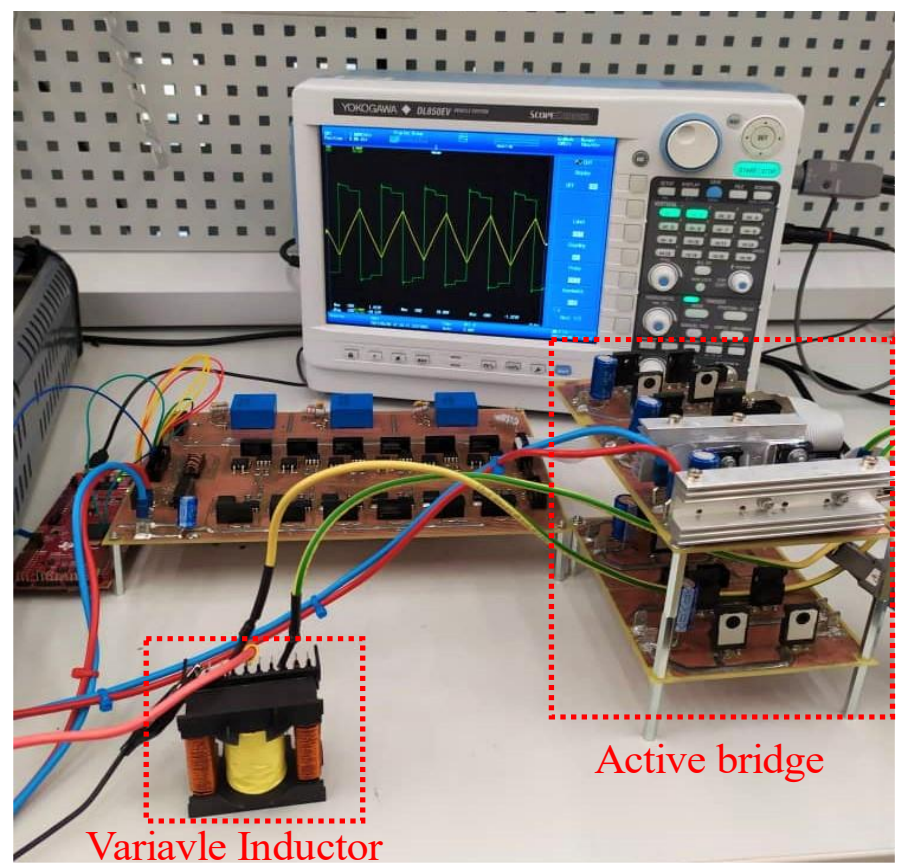

Figure 10. Hardware experimental test setup of the variable inductor. 
Table 3. Components of the experimental test setup.

\begin{tabular}{cc}
\hline Core size & ETD49/25/16 \\
Magnetic material & $\mathrm{N} 87$ \\
$\Delta \mathrm{L}$ & $42-105 \mu \mathrm{H}$ \\
Micro controller & ti delfino f28379d \\
Gate driver & HCPL-3120 \\
IGBT & FGH40N60SFD \\
Input voltage of active bridge & $0-50 \mathrm{~V}$ \\
Frequency & $50 \mathrm{kHz}$ \\
\hline
\end{tabular}

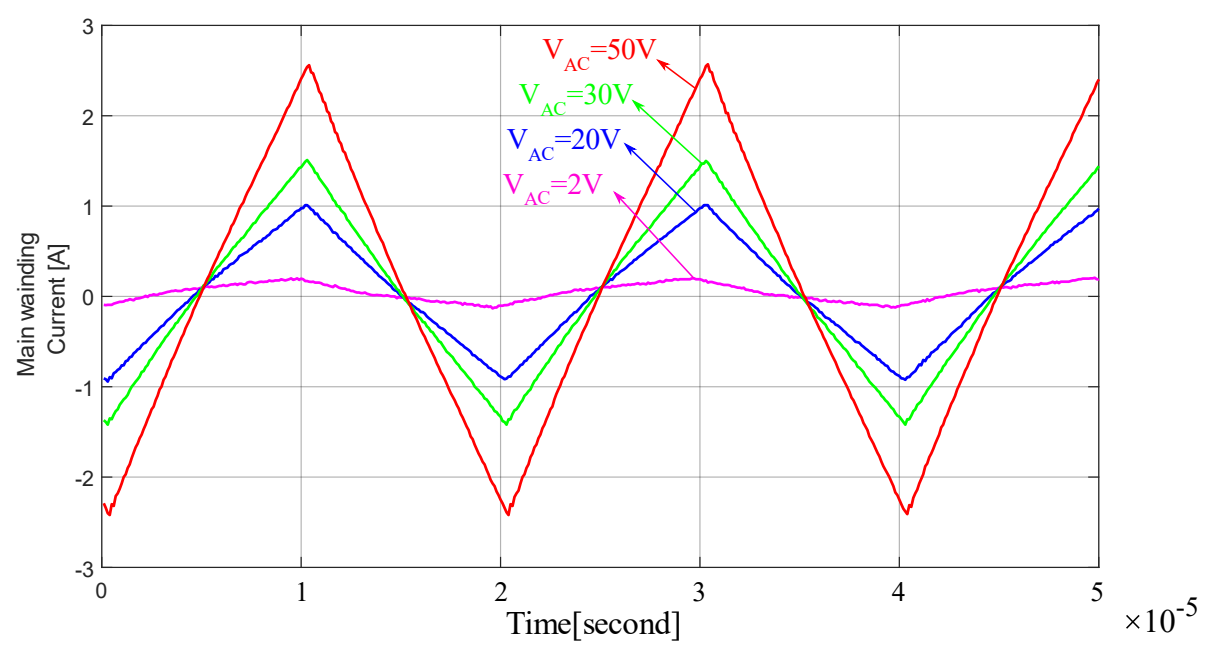

Figure 11. AC current waveform of the main winding.

Figure 11 shows the current waveform of the main winding under different voltage levels during the experiments. The active bridge generates squared waveforms with the frequency of $50 \mathrm{kHz}$, which corresponds to have triangle waveform of current in the main winding of the variable transformer. The inductor is tested under four different voltage levels. The peak value of the AC voltage waveform is $2 \mathrm{~V}, 10 \mathrm{~V}, 20 \mathrm{~V}, 30 \mathrm{~V}$, and $50 \mathrm{~V}$. Each voltage level leads to produce a different value of AC current in the main winding. For each case, the bias current is changed from 0 to 2 amps with the step of $10 \mathrm{~mA}$ in order to collect enough data for the neural network's training, with different AC currents and bias currents.

In order to find the inductance of the variable inductor in experimental, AC winding voltage and current were measured. Then, by replacing measured values in Equation (13), the value of inductance was found, where $\mathrm{V}_{\mathrm{AC}}$ shows the RMS value of the first harmonic of AC winding voltage, IAC represents the RMS value of the first harmonic of AC winding current, and $\mathrm{f}$ is the switching frequency.

$$
L=\frac{X_{L}}{\omega}=\frac{\frac{V_{A C}}{I_{A C}}}{2 \pi f}
$$

Figure 12 shows the change of inductance as a function of the bias current for different $\mathrm{AC}$ voltages. 


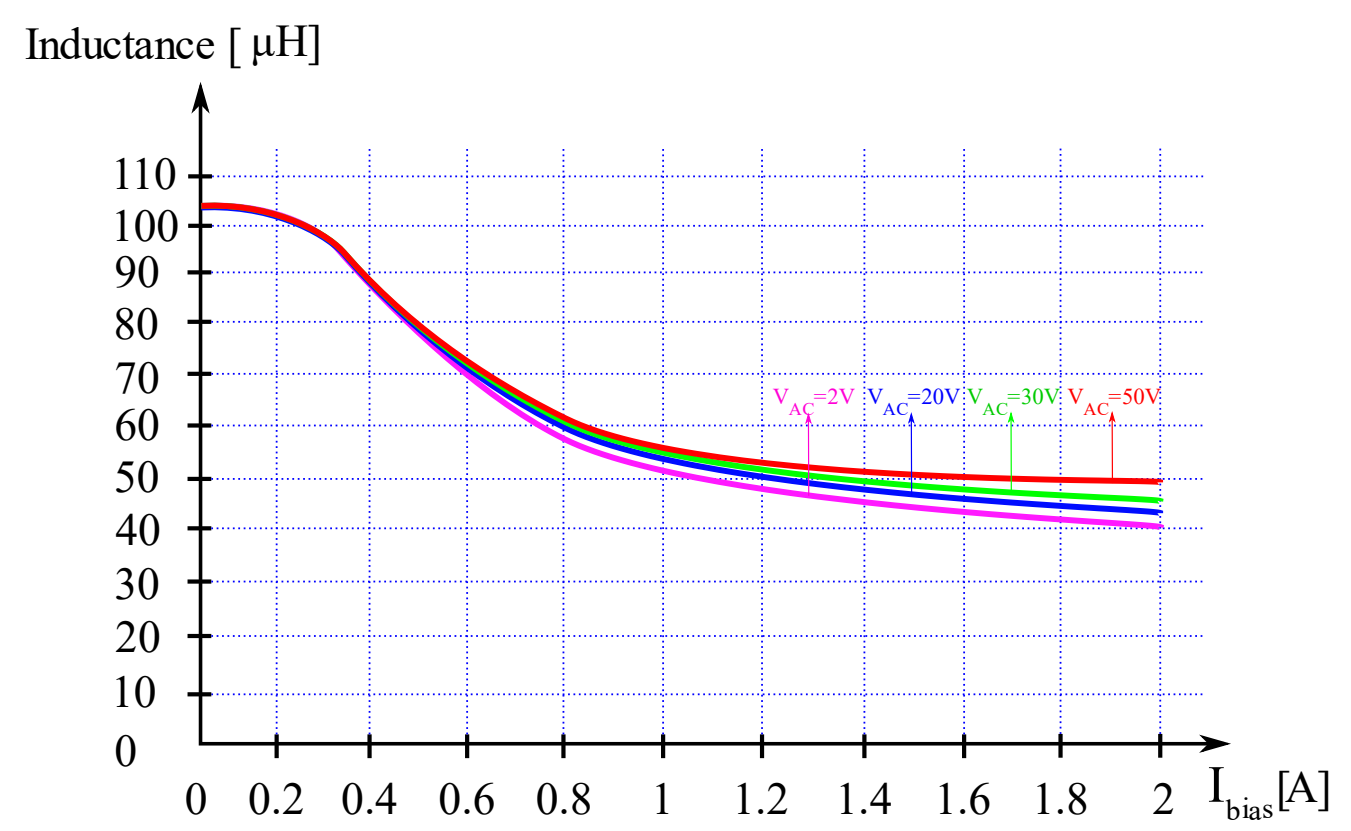

Figure 12. The change of inductance as a function of bias current for different AC voltages.

\section{Validation of the Proposed Model}

In order to validate the results, randomly $80 \%$ of the experimental results are used for training, and $20 \%$ of the results are used for validation of the derived model. Figures 13 and 14 depict the actual data compared to the prediction data for training data and validation data. As it can be seen in both figures, the derived model has great accuracy for both.

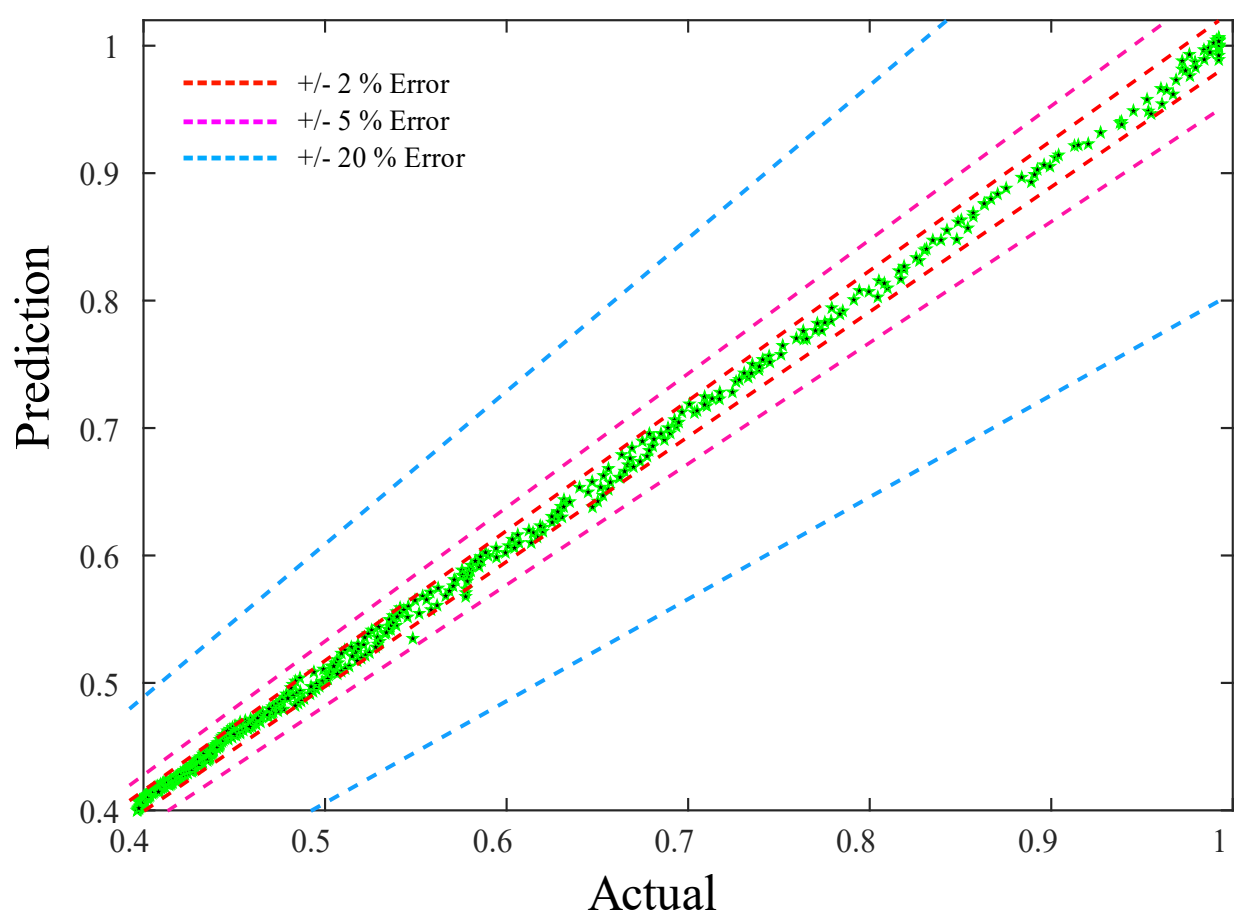

Figure 13. Train result. 


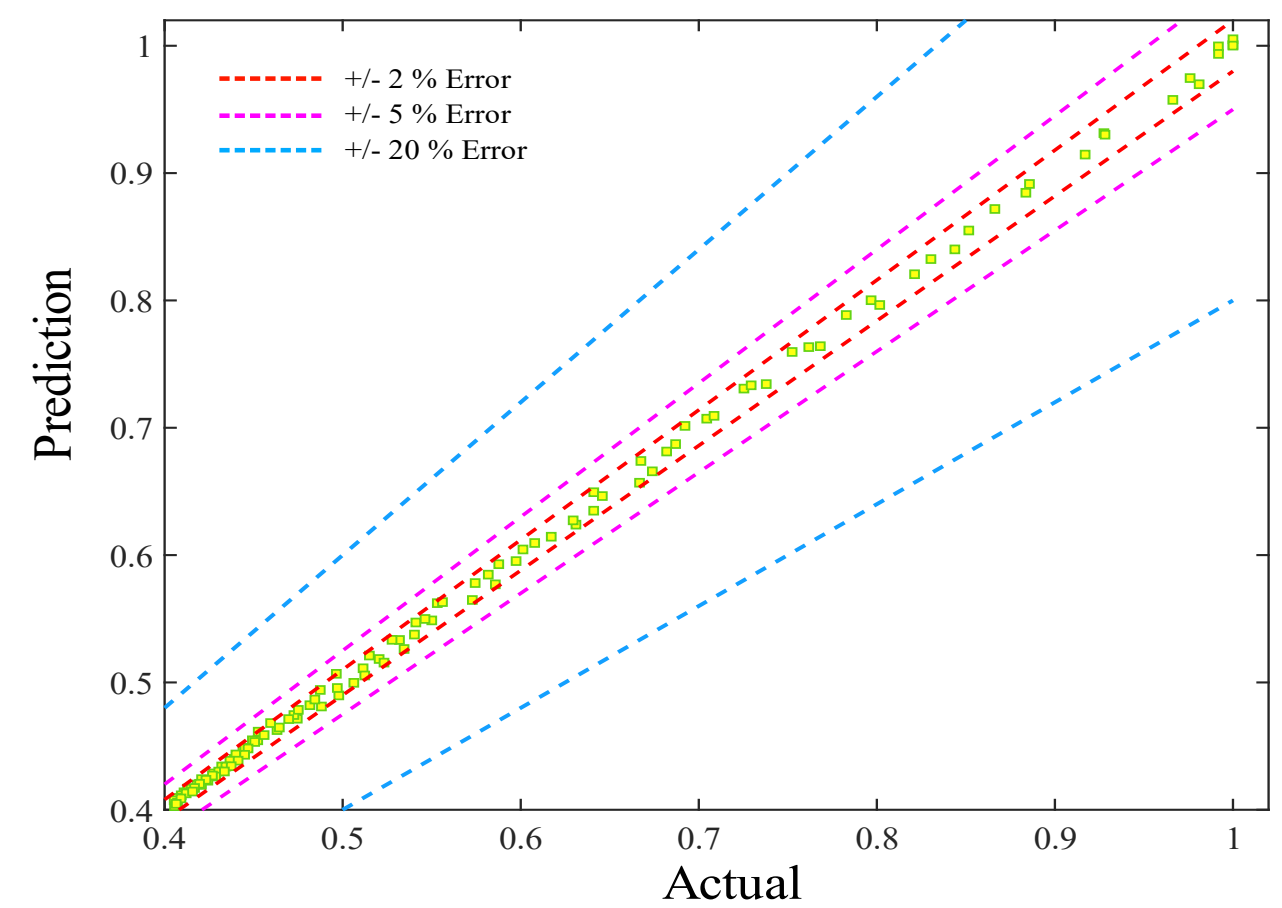

Figure 14. Validation results.

In order to evaluate the accuracy of the model, the coefficient of determination is calculated by Equation (14).

$$
R^{2}=1-\frac{\sum_{i}\left(y_{i}-y_{M}\right)^{2}}{\sum_{i}\left(y_{i}-f_{i}\right)^{2}}
$$

where $y_{i}$ represents the observations based on the experiments, $y_{M}$ represents the mean value of the observations, and $f_{i}$ represents the predicted results by the derived model. The coefficient of determination is 0.99234 for training data and 0.99931 for validation results, which implies that the derived model has excellent accuracy.

\section{Conclusion}

In this paper, a new method for calculating the inductance of the variable inductance in the nonlinear area has been proposed. GMDH neural networks have been used in this paper where instead of hidden function over a distributed network, a mathematical model based on polynomial equations is derived out for the model. Experiments have been carried out for training and validation of the proposed model. It is shown that the derived model has tremendous accuracy for both training and validation data. The effect of the temperature will be considered in future work.

\section{References}

[1] B. Chen, X. Liang, and N. Wan, "Design Methodology for Inductor-Integrated Litz-Wired High-Power Medium-Frequency Transformer with the Nanocrystalline Core Material for Isolated DC-Link Stage of Solid-State Transformer," IEEE Trans. Power Electron., 2020.

[2] M. S. S. Nia, P. Shamsi, and M. Ferdowsi, "Investigation of Various Transformer Topologies for HF Isolation Applications," IEEE Trans. Plasma Sci., vol. 48, no. 2, pp. 512-521, 2020.

[3] K. Zhang et al., "Accurate calculation and sensitivity analysis of leakage inductance of high-frequency transformer with Litz wire winding," IEEE Trans. Power Electron., vol. 35, no. 4, pp. 3951-3962, 2019. 
[4] H. Fan and H. Li, "High-frequency transformer isolated bidirectional DC-DC converter modules with high efficiency over wide load range for 20 kVA solid-state transformer," IEEE Trans. Power Electron., vol. 26, no. 12, pp. 3599-3608, 2011.

[5] H. M. Suryawanshi and G. G. Talapur, "Resonant Converter for renewable energy with utilization of transformer magnetizing inductance as shunt element," in 2016 IEEE International Conference on Power Electronics, Drives and Energy Systems (PEDES), 2016, pp. 1-5.

[6] Y. Wei, Q. Luo, J. Wang, and S. Pengju, "Analysis and design of the DCM operation boost PFC converter with magnetic control," IET Power Electron., vol. 12, no. 14, pp. 3697-3706, 2019.

[7] Y. Liu, H. A. Mantooth, J. C. Balda, and C. Farnell, "A variable inductor based LCL filter for large-scale microgrid application," IEEE Trans. Power Electron., vol. 33, no. 9, pp. 7338-7348, 2017.

[8] G. Martínez, J. M. Alonso, and R. Osorio, "Analysis and design of a unidirectional resonant switched-capacitor step-up converter for OLED lamp driving based on variable inductor," IEEE J. Emerg. Sel. Top. Power Electron., vol. 6, no. 3, pp. 1106$1115,2018$.

[9] M. S. Perdigao, M. F. Menke, Á. R. Seidel, R. A. Pinto, and J. M. Alonso, "A review on variable inductors and variable transformers: Applications to lighting drivers," IEEE Trans. Ind. Appl., vol. 52, no. 1, pp. 531-547, 2015.

[10] E. Orietti, P. Mattavelli, G. Spiazzi, C. Adragna, and G. Gattavari, "Two-phase interleaved LLC resonant converter with current-controlled inductor," in 2009 Brazilian Power Electronics Conference, 2009, pp. 298-304.

[11] M. S. Perdigao, J. M. Alonso, M. A. Dalla Costa, and E. S. Saraiva, "Using magnetic regulators for the optimization of universal ballasts," IEEE Trans. Power Electron., vol. 23, no. 6, pp. 3126-3134, 2008.

[12] L. Zhang, W. G. Hurley, and W. H. Wölfle, "A new approach to achieve maximum power point tracking for PV system with a variable inductor," IEEE Trans. Power Electron., vol. 26, no. 4, pp. 1031-1037, 2010.

[13] S. Aldhaher, P. C.-K. Luk, and J. F. Whidborne, "Electronic tuning of misaligned coils in wireless power transfer systems," IEEE Trans. Power Electron., vol. 29, no. 11, pp. 5975-5982, 2014.

[14] A. A. Huzayyin, "Utilizing the nonlinearity of a magnetic core inductor as a source of variable reactive power compensation in electric power systems," in 2008 Annual IEEE Student Paper Conference, 2008, pp. 1-4.

[15] S. Saeed and J. Garcia, "Extended Operational Range of Dual-Active-Bridge Converters by using Variable Magnetic Devices," in 2019 IEEE Applied Power Electronics Conference and Exposition (APEC), 2019, pp. 1629-1634.

[16] M. Z. Youssef and P. K. Jain, "A review and performance evaluation of control techniques in resonant converters," in 30th Annual Conference of IEEE Industrial Electronics Society, 2004. IECON 2004, 2004, vol. 1, pp. 215-221.

[17] S. Saeed, J. Garcia, M. Perdigao, V. S. Costa, B. Baptista, and A. M. S. Mendes, "Improved inductance calculation in variable power inductors by adjustment of the reluctance model through magnetic path analysis," IEEE Trans. Ind. Appl., 2020.

[18] Y. Wei, Q. Luo, X. Du, N. Altin, J. M. Alonso, and H. A. Mantooth, "Analysis and design of the LLC resonant converter with Variable inductor control based on time-domain analysis," IEEE Trans. Ind. Electron., vol. 67, no. 7, pp. 5432-5443, 2019.

[19] N. Hou and Y. W. Li, "Overview and comparison of modulation and control strategies for a nonresonant single-phase dualactive-bridge DC-DC converter," IEEE Trans. Power Electron., vol. 35, no. 3, pp. 3148-3172, 2019.

[20] A. Burgio, D. Menniti, M. Motta, A. Pinnarelli, N. Sorrentino, and P. Vizza, "A laboratory model of a dual active bridge DCDC converter for a smart user network," in 2015 IEEE 15th International Conference on Environment and Electrical Engineering (EEEIC), 2015, pp. 997-1002.

[21] M. S. Perdigão, S. F. Ferreira, M. Martins, A. S. Mendes, and J. M. Alonso, "Finite element analysis of a variable inductor for an RSCC based LED lamp driver," in 2015 IEEE Industry Applications Society Annual Meeting, 2015, pp. 1-8.

[22] Y. Bi and D. C. Jiles, "Finite element modeling of an electrically variable inductor," IEEE Trans. Magn., vol. 35, no. 5, pp. 35173519, 1999.

[23] J. M. Alonso, G. Martínez, M. Perdigão, M. Cosetin, and R. N. do Prado, "Modeling magnetic devices using SPICE: Application to variable inductors," in 2016 IEEE Applied Power Electronics Conference and Exposition (APEC), 2016, pp. 11151122. 
[24] G. W. Ludwig and S.-A. El-Hamamsy, "Coupled inductance and reluctance models of magnetic components," IEEE Trans. Power Electron., vol. 6, no. 2, pp. 240-250, 1991.

[25] P. Mohammadi, R. Samanbakhsh, P. Koohi, and F. Ibanez, "High Frequency Transformer Design for Specific Static Magnetising and Leakage Inductances Using Combination of Multi-Layer Perceptron Neural Networks and FEM Simulations," in 2019 IEEE 10th International Symposium on Power Electronics for Distributed Generation Systems (PEDG), 2019, pp. 837-842.

[26] M. Iwasaki, H. Takei, and N. Matsui, "GMDH-based modeling and feedforward compensation for nonlinear friction in table drive systems," IEEE Trans. Ind. Electron., vol. 50, no. 6, pp. 1172-1178, 2003.

[27] S. Makhloufi and G. G. Pillai, "Wind speed and wind power forecasting using wavelet denoising-GMDH neural network," in 2017 5th International Conference on Electrical Engineering-Boumerdes (ICEE-B), 2017, pp. 1-5.

[28] M. S. Pukish, P. Różycki, and B. M. Wilamowski, "Polynet: a polynomial-based learning machine for universal approximation," IEEE Trans. Ind. Informatics, vol. 11, no. 3, pp. 708-716, 2015.

[29] D. Medini and S. Ben-Yaakov, "A current-controlled variable-inductor for high frequency resonant power circuits," in Proceedings of 1994 IEEE Applied Power Electronics Conference and Exposition-ASPEC'94, 1994, pp. 219-225.

[30] G. C. Onwubolu, GMDH-methodology and implementation in MATLAB. World Scientific, 2016. 